\title{
Pathophysiology of Demineralization, Part II: Enamel White Spots, Cavitated Caries, and Bone Infection
}

\author{
W. Eugene Roberts ${ }^{1}$ (1) $\cdot$ Jonathan E. Mangum ${ }^{2} \cdot$ Paul M. Schneider $^{3}$
}

Accepted: 15 December 2021 / Published online: 14 February 2022

(C) The Author(s) 2022

\begin{abstract}
Purpose of Review Compare noninfectious (part I) to infectious (part II) demineralization of bones and teeth. Evaluate similarities and differences in the expression of hard tissue degradation for the two most common chronic demineralization diseases: osteoporosis and dental caries.

Recent Findings The physiology of demineralization is similar for the sterile skeleton compared to the septic dentition. Superimposing the pathologic variable of infection reveals a unique pathophysiology for dental caries.

Summary Mineralized tissues are compromised by microdamage, demineralization, and infection. Osseous tissues remodel (turnover) to maintain structural integrity, but the heavily loaded dentition does not turnover so it is ultimately at risk of collapse. A carious tooth is a potential vector for periapical infection that may be life-threatening. Insipient caries is initiated as a subsurface decalcification in enamel that is not detectable until a depth of $\sim 400 \mu \mathrm{m}$ when it becomes visible as a white spot. Reliable detection and remineralization of invisible caries would advance cost-effective wellness worldwide.
\end{abstract}

Keywords Cost-effective $\cdot$ Healthcare $\cdot$ Wellness $\cdot$ Dental caries $\cdot$ White spot lesion $\cdot$ Remineralization

\section{Introduction}

Demineralization is the fundamental mechanism for loss of mineralized tissue [1-5]. The biomechanics of routine loading, parafunction, and aging results in accumulation of

This article is part of the Topical Collection on Craniofacial Skeleton

W. Eugene Roberts

werobert@iu.edu

Jonathan E. Mangum

jon.mangum@unimelb.edu.au

Paul M. Schneider

pmschn@unimelb.edu.au

1 American Board of Orthodontics, Indiana University \& Purdue University at Indianapolis, 8260 Skipjack Drive,

Indianapolis, IN 46236, USA

2 Translational Proteomics Laboratory, Department of Biochemistry and Pharmacology, Faculty of Medicine, Dentistry and Health Sciences, University of Melbourne, Corner Grattan Street and Royal Parade, Melbourne, Victoria 3010, Australia

3 American Board of Orthodontics, Melbourne Dental School, University of Melbourne, 720 Swanston St, Melbourne, Victoria 3010, Australia microdamage that compromises structural integrity. Bone remodels to repair microdamage, but teeth are exposed to irreversible degradation due to attrition, abrasion, erosion, and abfraction [1]. Decreased mass of bones and teeth risks structural failure due to atraumatic fractures or cavitated caries. The etiology of demineralization involves acid produced by clastic cells or microbic metabolism [2-5]. Acidic fluid bathing calcified tissues dissociates the mineral component of hydroxyapatite (HA). The process may be physiologic, environmental, or pathologic [1]. Noninfectious demineralization was addressed in part I of this review. Part II of this clinically oriented series focuses on pathology of infection superimposed on the physiology of mineralized tissues. The pathophysiologic emphasis is on the most prevalent pandemic disease in the world: dental caries [4-8].

\section{Infections}

Lactic acid and any other organic acids $[4,5]$ produced by oral microbes tip the solubility equilibrium of HA toward dissolution for exposed dental tissues. The cariogenic microbes are nourished by the biofilm (plaque) that support a demineralization defect as it is formed [6-8]. Fluoride is a natural mineral 
in the environment that plays an important role in enamel physiology. Inter-rod substance (sheath) is more porous than the enamel rods. When there is optimal fluoride ion (F-) in the oral environment, the fluid component of saliva percolates through the enamel preferentially protecting the sheaths from demineralization by formation of fluorapatite (FA) via ion substitution during physiologic remineralization [1]. Thus, the enamel rods (HA prisms) are at greater risk of demineralization by the acidic challenge from active caries resulting in scooped-out deficits on the enamel surface (Fig. 1). Virulent microbes within plaque colonize the shallow defects $(\geq 10 \mu \mathrm{m}$ deep) to initiate an active carious lesion that is self-sustaining via fermentable carbohydrates in the diet [1]. The anti-caries effect of $\mathrm{F}^{-}$is an ion exchange with hydroxyl $\left(\mathrm{OH}^{-}\right)$groups of HA to form FA. The biologic form of FA is a very stable, tight-packed apatite structure that is resistant to the acidic elevation of solubility equilibrium that would otherwise initiate enamel rod demineralization (Fig. 1) [1, 11]

Carious teeth are a potential vector for deep sepsis into bone that can result in painful and even life-threatening infections [1]. Pathophysiology is similar for dental and skeletal sepsis. Initial carious lesions in enamel (Fig. 1) are like infections in nonvital bone. Initial infection of dead bone, enamel, and cementum are all supported by microbe-laden biofilm [9-11]. Microbes must maintain an extravascular source of nutrition and waste disposal because there is no access to host vascularity. However, once the infection invades vital tissue such as dentin $[4,5,12]$, the pathogenesis is similar to progressive infections in living bone [13]. The morphology of the lesions may be lytic, sclerotic, or a combination of the two

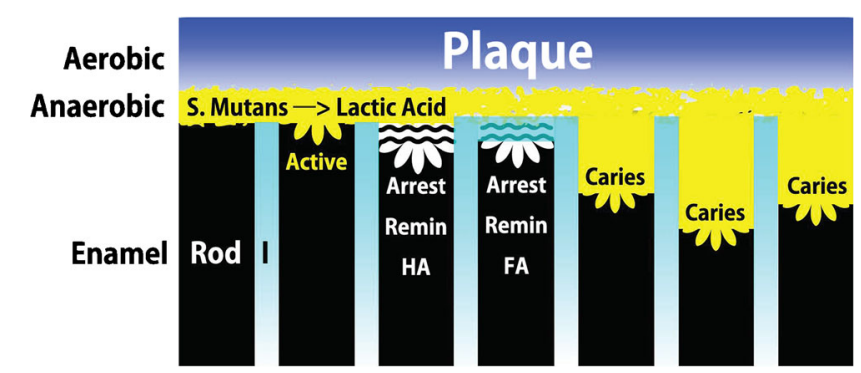

Fig. 1 Based on the evidence reviewed, a schematic diagram of a plaquecoated enamel surface shows the principal stages of enamel pathophysiology relative to demineralization, remineralization and infectious dental caries. The superficial layer of plaque is aerobic, while the inner layer adjacent to the enamel surface is anaerobic. Enamel rods are separated by inter-rod substance (I) which has a more porous crystalline structure which allows percolation of fluoride to produce fluorapatite (FA). It is hypothesized that the inter-rod concentration of FA (cyan color gradient) is greatest near the oral surface and decreases with depth. Under anaerobic conditions, S. Mutans produces the lactic acid that facilitates active demineralization. Progressive caries preferentially demineralized the rods (HA prisms). From the left, black enamel rods depict stages of the pathophysiology: (1) intact rod, (2) active surface demineralization, (3) arrested lesion remineralized with HA, (4) arrested lesion remineralized with FA, and (5-7) active carious infection. See text for details
[14]. Although dental caries may be associated with mechanical factors and chemicals, it is essentially an infection related to hygiene and diet [4-8]. Cementum exposure to the oral cavity increases with age as soft tissue recedes exposing the roots of teeth. The mineralized surface of a root (cementum) is more susceptible to plaque-induced caries than enamel because it is less densely mineralized and more susceptible to plaque retention [15].

The etiology and pathogenesis of biofilms (plaque) are best studied in sophisticated in vitro models [16]. The virulent bacteria in plaque are primarily Streptococcus mutans (S. Mutans) as well as numerous Lactobacillus species that metabolize dietary sugar to produce lactic acid. Epidemiology suggests that $S$. mutans is the predominant microbe, and its prevalence has more impact on caries risk than sugar consumption and poor oral hygiene [17]. Relative to the discussion of mineralized tissue infection, dental decay is clearly a plaque-dependent process which begins with pellicle, an acellular proteinaceous film formed by the saliva that coats all oral mineralized surfaces. Microbes attach to pellicle and form a biofilm which increases in volume to evolve into a dental plaque with a superficial aerobic zone and a deep anaerobic layer next to the enamel surface (Fig 1). In contrast to anaerobic bone infections [14], the cariogenic bacteria are nourished by the diet and particularly sugars that permeate the plaque. As will be discussed in detail in the subsequent caries section, the most virulent aspect of the disease process occurs in the anaerobic environment where $S$. mutans metabolism produces acid via fermentation. The decreased $\mathrm{pH}$ of plaque fluid attacks the enamel rods, cementum, and exposed dentin. As a facultative anaerobe, S. mutans produces adenosine triphosphate (ATP) by aerobic respiration if oxygen is present, but it is capable of switching to fermentation if oxygen is absent. S. mutans is naturally present in the human oral microbiota, along with at least 25 other species of oral streptococci, and each species has specific properties for colonizing in a specific niche $[4,5,11,12]$. Although the disease process is well known, the prevention and treatment of dental caries is problematic. A few antimicrobial peptides display a remineralizing effect on HA [18], but hygiene and professional prophylaxis are the mainlines of defense. Caries is a communicable disease that must be inoculated with specific virulent bacteria [19].

If fermentable carbohydrates are consumed regularly, cariogenic bacteria may sufficiently compromise tooth and bone structure to produce serious bone infections. A particular concern is a fistula draining a periapical abscess into a body space like the floor of the mouth. In the absence of effective healthcare, body space infections are fatal. Prior to antibiotics, body space infections had a poor prognosis even in developed countries. In the era of modern antibiotics, odontogenic body space infections continue to be complex, life-threatening problems [20]. In a recent sample $(n=256)$, a dental abscess 
origin was found for $76 \%$ of body space infections in the head. Despite surgical drainage and antibiotics, three were fatal [21•]. Ludwig's angina with airway compromise continues to be a serious complication for uncontrolled caries infections [22]. An additional serious sequela for bone infections is septicemia which is usually associated with (1) compromised immune system [23], (2) resistant strains of bacteria due to misuse of antibiotics, and (3) failure to eliminate the source of the infection [24]. Caries is a serious health challenge. Furthermore, dental negligence is an invitation to serious medical problems worldwide $[25,26]$. The Healthcare Effectiveness Data and Information Set (HEDIS) documents that compromised dental health is associated with poor adherence to preventive measures for cancer and retinopathy, as well as for glycemic and blood pressure control for potential diabetics [26]. Health and wellness are closely related.

Decalcification and remineralization of all mineralized tissues contribute directly or indirectly to calcium homeostasis. However, percolation of calcium ions from nonliving enamel is via dentin [1]. Caries is initiated as an enamel subsurface demineralization that is morphologically similar to catabolic bone modeling on periosteal surfaces, particularly renal osteodystrophy (ROD) [27, 28]. Furthermore, the intracortical resorption of metacarpal bones with advanced ROD is reminiscent of white spot lesions (WSLs) which are carious lesions with a superficial veneer of enamel (Fig. 2) [29•]. More persistent ROD associated with deep penetration of the cortical bone along phalanges is like cavitated caries. In addition, noncavitated caries are morphologically similar to resorption cavities during bone remodeling $[2,3,30]$ or the osseous radiolucencies defined as traumatic cysts [31].

Caries is responsible for many periapical bone infections of the jaws (prevalence $>62 \%$ ) [32], while periodontitis, an alveolar bone infection, results in a loss of bone support (prevalence $11 \%$ ) [33]. OP is a metabolic bone disease rather than an infection. There is no clear relationship between OP and periodontal bone loss [34]. Caries is a dental (odontogenic) infection that may result in pulp degeneration and spread into the supporting jaw bone $[20,21 \cdot, 22,35]$. These are typically polymicrobial infections involving various facultative and strict anaerobes [35].

\section{Osteomyelitis}

Caries-related bone infections are a form of osteomyelitis $(\mathrm{OM})$, i.e., inflammation of bone and marrow tissue. Odontogenic bacterial or fungal infections may spread to deep fascial spaces and can lead to septicemia if not effectively managed. Efficient treatment is to eliminate the source of the infection such as a carious tooth; antibiotics are used as adjunctive therapy $[20,21 \cdot 22]$. A necrotic pulp that is devitalized by caries results in periapical osseous infections with the microbes from the carious lesion. Advancement of

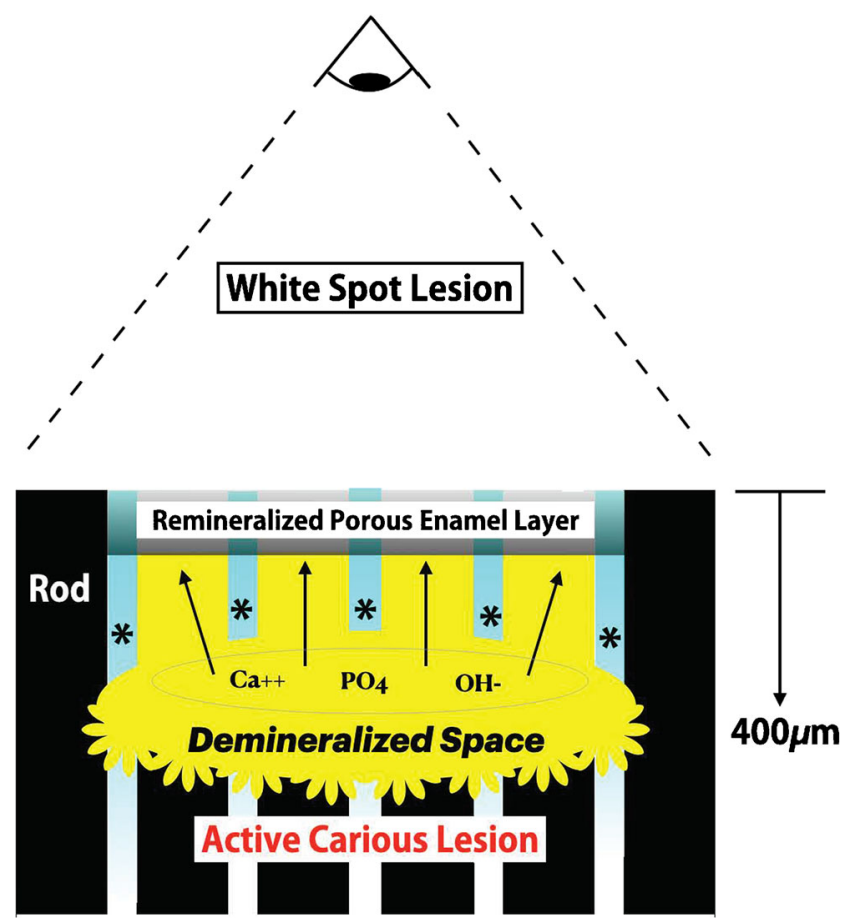

Fig. 2 In a 2D section, a WSL is viewed from above as a white discoloration surrounded by intact enamel that reveals the subsurface location of a demineralized space $\geq 400 \mu \mathrm{m}$ in depth. It is hypothesized that mineralized inter-rod substance (asterisk) is less susceptible to demineralization because of natural FA formation via intercrystalline percolation. As the FA gradient decreased with depth, the active carious lesions progress laterally and coalesce to form a demineralization space. The lesion is invisible until it reaches a depth of $\sim 400 \mu \mathrm{m}$ when light diffraction is adequate for the demineralized space to be visualized as a subsurface WSL. Evidence suggests the superficial remineralized porous enamel layer is a product of residual enamel not destroyed by the initial surface demineralization that is supplemented by remineralization via calcium $\left(\mathrm{Ca}^{++}\right), \mathrm{PO}_{4}$, and $\mathrm{OH}^{-}$moving toward the surface (black arrows). The source of the ions for remineralization is from HA destruction by the active carious lesion at the base of the demineralized space. See text for details

the infection is similar to caries attacking vital dentin. Bacteria laden biofilms support infection within the dead bone [36] which is a particular problem for orthopedic implant failure [37]. The bacteria feed off the dead tissue in an anaerobic environment. Because the infected tissue tends to be avascular, OM is difficult to resolve with antibiotics [36]. Similar to the surgical excision of active caries with operative dentistry $[38,39]$, osseous resection is often required to resolve $\mathrm{OM}$ $[13,14,40]$.

OM of the jaws may be caused by dental sepsis (caries), oral surgical procedures, or facial fracture (trauma). The pathology may be an acute abscess, but most OM of the jaws is diagnosed from routine dental radiographs. Asymptomatic pathology is usually a relatively innocuous, localized lesion that grows slowly. Depending on the virility of the infection, OM may appear to be an area of osteolysis or condensing osteitis in a radiograph [41]. Endodontics and restorative dentistry are usually effective for controlling the source of the infection. 
Well-managed extensive periapical lesions heal spontaneously. An infection that fails to respond to conservative therapy and antibiotics may be a relatively avascular lesion. Dead bone supports an infection much like cavitated caries, so surgical resection is required [42]. Caries are currently managed with expensive surgical and restorative procedures, i.e., operative, endodontic, and prosthodontic dentistry. However, advances in early caries detection and remineralization therapeutics may redirect dental practice toward prevention. Surgical correction of caries to prevent bone infections and their serious sequelae is neither efficient nor cost-effective.

$\mathrm{OM}$ of dental origin is usually an opportunistic infection caused by a mixture of Alpha hemolytic streptococci and anaerobic species from the oral cavity [43]. Because of skin exposure, OM of the traumatized jaws or long bones are typically Staphylococcus aureus infections [44]. The mandible is affected more commonly than the maxilla probably because the latter has greater vascularity, relatively thin cortical plates, and fewer large medullary spaces. Decreased vascularity of mandibular bone renders it more susceptible to medicationrelated osteonecrosis of the jaw (MRONJ) associated with resorption-inhibiting drugs [45]. A history of antiresorptive drug therapy may be associated with compromised orthodontic outcomes [46].

Periodontal bone infections are a different manifestation of oral OM. Porphyromonas gingivalis is a gram-negative anaerobic pathogen found in subgingival plaque associated with progressive periodontitis [47]. Changes in the oral environment such as orthodontic treatment with fixed appliances and aligners may alter the microbiome of the oral cavity [48]. Significant increases are noted in anaerobic and facultative anaerobes in both plaque and saliva. Fixed orthodontic appliances induced measurable changes in the oral microbiome including a relative abundance of obligate anaerobes that are periodontal pathogens [49]. For a healthy dentition, fixed orthodontic treatment has a transient effect on periodontal health that is ameliorated after removal of the appliances [50], but enamel decalcifications due to high levels of cariogenic bacteria are common [51]. Orthodontics may alter the oral microbiome, but the periodontal effects after treatment are reversible [52].

\section{Caries}

Caries is a unique infection of mineralized tissue caused by biofilm (plaque) containing primarily two species of virulent bacteria: streptococcus and lactobacilli $[4,5]$. Fermentation of dietary carbohydrates produces lactic acid which demineralizes the enamel surface at the plaque interface. A complex demineralization and remineralization cycle related to diet results in a subsurface carious lesion that is covered with what appears to be an intact enamel surface [53]. The pathogenesis of these unusual lesions is clarified with quantitative polarized light analysis of histologic sections [54•] and scanning electron [55.] microscopic studies of lesions induced by 1-4 weeks at the interface of specifically designed plaque-filled spaces beneath orthodontic bands. The device is a simulation of band with intact (control) enamel surfaces which show some demineralization within $10 \mu \mathrm{m}$ of the oral surface [54•]. In the absence of plaque, these potential lesions are limited by saliva-mediated remineralization [6-8]. However, constant plaque contact results in universal enlargement of intercrystalline spaces between the enamel rods. Some enamel pores increase to $\sim 1 \mu \mathrm{m}$ in diameter [55•] which allows nutritive carbohydrates to diffuse into the subsurface lesion (demineralized space). An active subsurface caries process deepens the lesion by eroding $\mathrm{Ca}^{++}$and $\mathrm{PO}^{3-}$ at the enamel interface (Fig. 2). These ions escape into saliva through the enamel pores as the lesion advances beneath a largely intact enamel surface that is up to $\sim 9 \mu \mathrm{m}$ in thickness [54•]. The outer visually intact surface is composed of original enamel that was resistant to demineralization that has been supplemented by remineralization of interprismatic substance [56] with $\mathrm{Ca}^{++}$and $\mathrm{PO}_{4}{ }^{3-}$ produced by active caries in the subsurface lesion. Intra-enamel caries is invisible until the lesions reach a depth of $\sim 400 \mu \mathrm{m}$. Backscattering of incident light by the subsurface demineralized region is directly related to lesion depth [57]. When a lesion is $400 \mu \mathrm{m}$ deep, the backscatter effect is sufficient to visibly detect the decalcified lesion as a white spot $[58,59]$. Figure 2 is a summary of the unique pathogenesis of invisible subsurface lesions that evolve into white spots and may eventually cavitate.

Dental caries is a common oral disease with a complex epidemiology relative to lifestyle, nutrition, and hygiene proficiency. For instance, the disease is more prevalent in cultures consuming carbonated beverages (soft drinks) [60]. Obese children are particularly prone to caries because of habitual carbohydrate-rich snacks between meals [61]. Pits, fissures, restoration margins, and other continuity defects in enamel are predisposed to caries $[4,62]$, but smooth surfaces are at risk if they are covered with plaque $[6,7,54 \bullet, 55 \bullet$. An acidic $\mathrm{pH}$ at the enamel surface facilitates the demineralization process [5]. The $\mathrm{pH}$ in plaque is depressed for about an hour after each ingestion of acidic food [63], beverages [64], drugs [65, 66], mouthwash [67], and fermentable carbohydrates [4, 5]. Dietary acidity has an accumulative demineralization effect that facilitates caries. Carious lesions in nonvital enamel require the nourishment of sugar or other fermentable carbohydrates from the diet (Fig. 2). However, once the virulent organisms penetrate in living dentin, they are no longer dependent on the diet for nutrition because they live off the tissue they destroy [5]. The odontoblasts in the pulp have cellular processes that penetrate the dentin to the DEJ. When the carious infection enters dentin, there may be an uncomfortable sensation, but no obvious symptoms are apparent until the dental pulp is threatened or infected [1]. Odontoblasts can 
sense the inflammatory reaction of approaching caries and then resist the carious attack by forming secondary dentin to protect the pulp from infection [12].

\section{Incipient Lesions}

Pellicle formed by salivary proteins coats all intraoral mineralized tissue surfaces. It is a double-edged sword with respect to caries protection. Pellicle protects enamel surfaces from demineralization by acidic foods and saliva [54•], but it is also the foundation for cariogenic biofilm (plaque) that adheres to all mineralized tissues in the oral cavity [68-71]. It is important to reiterate that intra-enamel caries that develop into WSLs are not visible until the noncavitated subsurface porosity reaches a depth of about $400 \mu \mathrm{m}$ (Fig. 2) [57]. Reliable detection of invisible caries in lesions as shallow as $20 \mu \mathrm{m}$ would be valuable for assessing the risk of fixed appliances prior to orthodontic treatment. As subsequently discussed, multiple available and developmental technologies are being evaluated in this regard $[4,5,72]$. However, there is no innocuous method available for detecting invisible carious lesions before characteristic white spots become visible. Preventative measures such as photodynamic control of cariogenic bacteria [73], F- varnish [74], and particularly remineralization are more effective for managing shallow lesions $(\leq 20 \mu \mathrm{m})$ [75]. A lack of proven technology to detect and assess early carious lesions (say $<100 \mu \mathrm{m}$ ) in enamel is a major deficit in clinical practice because caries intervention and remineralization technology should only be used when indicated. For example, fluoride varnish is a risk for allergic reactions [76]. The risk and expense for prevention and remineralization procedures in patients with no signs or symptoms of caries is only justified by a reliable diagnosis of invisible intra-enamel lesions.

\section{Caries Classification}

The International Caries Detection and Assessment System (ICDAS) established an integrated system for measuring caries that was designed to facilitate clinical research, particularly epidemiology [77]. A seven-point ordinal scale scores sites from sound enamel to extensive cavitation. It is an appropriate method for research but too complex and time-consuming for routine clinical practice. The American Dental Association (ADA) followed up with a relatively simple classification for caries that distinguishes between cavitated and noncavitated lesions [78]. Advanced (cavitated) lesions, root surface caries, and pit and fissure defects are common clinical problems that have important health implications; however, that subject is outside the scope for this review. The current objective is to compare sound enamel surfaces to incipient caries (invisible or white spots) within the context of bone physiology, calcium metabolism, and biomechanics [79].
WSLs are noncavitated, potentially reversible carious lesions that are entirely within enamel $[80,81]$. The pathophysiology of interest is comparison of sound enamel to an initial lesion [82]. In diagnosing an incipient lesion (invisible or white spot), it is important to score the defect as either an active or arrested lesion [83]. Sound enamel has normal translucency with a smooth, hard surface. A slight demineralization of an enamel surface (say $<100 \mu \mathrm{m}$ deep) is an invisible carious lesion that tends to be slightly more opaque with a loss of enamel luster [83]. Under routine clinical conditions, subsurface caries $<400 \mu \mathrm{m}$ deep are invisible [57]. Intra-enamel lesions are typically covered with plaque which is easily disclosed with stain. A plaque-covered enamel surface may feel increasingly rough as the tip of an explorer engages pores that support a subsurface active lesion. There are no clinical methods available for reliably detecting invisible lesions per se. Once intra-enamel caries reaches a depth of about $400 \mu \mathrm{m}$, they become visible as white spots [57]. Current diagnostic technologies such as electrical conductance and quantitative laser fluorescence (QLF) [84] have about the same sensitivity $(\sim 400 \mu \mathrm{m})$ as visual inspection, so neither method offers any real advantage for reliably detecting invisible caries. Crosspolarization optical coherence tomography is a useful research tool for imaging the internal structure of white spots [82], but the clinical utility of this method has not been demonstrated.

If the cariogenic microbes driving an enamel infection are devitalized, the lesion is arrested (Fig. 1), and the carious front remineralizes to become densely mineralized with an off-color hue (white, brown, or black) that is shiny, hard, and smooth [83]. Arresting carious lesions with the medical disinfectant silver nitrate $\left(\mathrm{AgNO}_{3}\right)$ which was referred to as "Howe's solution" was a common clinical procedure in the nineteenth century [85]. After sodium fluoride $(\mathrm{NaF})$ was established as an anti-caries agent in the twentieth century [86], an improved variation of the Howe's procedure was to disinfect the lesion with $\mathrm{AgNO}_{3}$ and then apply $\mathrm{NaF}$ to achieve a dense caries resistant layer via remineralization. In current practice, $25 \%$ $\mathrm{AgNO}_{3}$ nitrate followed by $5 \% \mathrm{Na}$ fluoride or $38 \% \mathrm{Ag}$ diamine fluoride are capable of arresting caries and promoting remineralization [85-87]. Unfortunately, the Ag component of the disinfectant permanently stains the arrested lesion black. That may be an acceptable outcome for posterior teeth in aging and young patients, but it is esthetically unacceptable for the dental surfaces that are exposed when smiling.

\section{Detection and Assessment of White Spots}

WSLs are focal subsurface decalcifications in enamel that are common iatrogenic problems associated with extended plaque retention (Figs. 1 and 2) [88,89]. Any irregularity along an enamel surface (fracture, chip, crack, or bonded attachment) may retain plaque and be cariogenic. In addition, plaque 
adhering to exposed oral bone sequestra inflame the surrounding mucosa [46, 90-92]. From a physiologic perspective, WSLs are localized pathologic processes (caries) that may or may not be active [83]. From an osseous perspective, a WSL is analogous to some manifestations of negative calcium balance, i.e., accelerated bone remodeling [30] or relatively quiescent bone cysts [31]. It is clear that bones and teeth are susceptible to severe destruction in the presence of sustained demineralization. During routine clinical examination, WSLs are commonly associated with obscure (interproximal) cavitated lesions [80] particularly if there is extensive plaque accumulation near gingival margins $[4,5]$. However, WSLs can occur in any protected area that is not cleaned by the mechanical action of soft tissue, inserting and removing a removable appliance [93], or oral hygiene procedures [59, 73, 89].

There are no documented reports for decalcifications with removable aligner treatment [94], which is curious because numerous online blogs and practitioner websites suggest it is a serious problem for patients with poor hygiene and a cariogenic diet [95]. The principal concern is plaque accumulation both on teeth and inside the aligners [71]. In addition, an aligner may inhibit the natural buffering and cleansing effect of saliva $[4,5,88]$. Risky behavior is a patient with poor hygiene who consumes fermentable carbohydrates $[4,5,88]$, prior to placing an aligner. An environment is created for WSLs or generalized decalcifications concentrated at the cusp tips [95]. Biofilm can also form inside aligners and on underlying enamel surfaces particularly if there are bonded attachments $[71,95]$. Fermentable carbohydrates in the diet are serious concerns for aligner treatment. Reportedly teeth covered by aligners are susceptible to generalized decalcifications $[60$, $61,95]$. Plaque removal from enamel surfaces and around attachments is heavily dependent on hygiene measures. Furthermore, an aligner shields teeth from the mechanical action of the soft tissues and may inhibit buffering and remineralization by saliva $[4,5,95]$. Although clinicians may have observed these problems, it is important to note that no documented reports are published [94]. Similar to removable functional appliances [93], aligners may mechanically remove plaque from tooth surfaces when they are inserted, worn, and removed. Fixed appliances are clearly the most important risk factor for WSLs because the prominent devices and bonding materials promote retention of cariogenic plaque $[89,96]$.

\section{Etiology of WSLs}

The etiology for WSLs is cyclic periods of demineralization due to acid attack after fermentable carbohydrate consumption $[4,88]$ followed by remineralization during the between meal/snack resting period [81]. The initial invisible foci are propagated by cariogenic bacteria that produce and invade defects in the enamel surface created by demineralization of enamel rods (Fig. 1) [4-7]. Within individual carious sites, anaerobic metabolism of cariogenic bacteria within biofilm produces primarily lactic acid from dietary sugar. Once early subsurface lesions are established, the cariogenic bacteria and their supporting biofilm are resistant to mechanical abrasion; however, a lesion within enamel remains dependent on fermentable carbohydrates from the diet for nourishment [4-7]. As the demineralized foci deepen $>20 \mu \mathrm{m}$, they may coalesce into a large subsurface lesion with a front of cariogenic bacteria that continue the caries process (Fig. 2) [53, 54•]. The calcium and phosphate ions freed by the demineralization process at the carious front move away from the active front of the lesion and supplement the porous enamel layer over a WSL (Fig. 2). Remineralization occurs in the inter-rod sheath, along the residual enamel veneer, or by partially filling-in enamel pores $[53,54 \bullet, 55 \bullet$. Thus, WSLs evolve a distinct morphology: hard enamel surface with an underlying demineralized cavity that appears white relative to the surrounding sound enamel $[89,96,97]$. The internal disease process is elucidated with polarized microscopy and microradiographic images of tooth sections that are cut perpendicular to the lesion [54•, 98, 99]. Raman microscopy is also capable of detailed imaging of a lesion [29]. Natural and induced WSLs show four histologic zones: (1) intact surface layer (ISL), (2) body of the demineralized lesion (white opacity), (3) dark zone (base of the demineralized area), and (4) translucent zone (advancing front of the lesion) [29•, 54•]. In effect, a WSL is an activation (A) of microbial resorption (R) in enamel that bears similarities to an osteoclast front resorbing the interior aspect of cortical bone during catabolic modeling $(\mathrm{A} \longrightarrow \mathbf{R})$ [27]. Reversal of $\mathrm{R}$ leads to formation (F) during bone remodeling $(\mathrm{A} \rightarrow \mathrm{R} \rightarrow \mathrm{F})$, but coupling may be arrested so the initial phase of remodeling $(\mathrm{A} \longrightarrow \mathbf{R})$ produces a residual resorption cavity $[2,3]$. Furthermore, the acidic front of the cariogenic microbes in a WSL is similar to the clear "sealing zone" of osteoclasts resorbing bone [100].

The inter-crystalline spaces within the rod sheath are larger and more permeable than the rods themselves [55•]. Morphology is consistent with increased fluid flow (percolation) to support turnover of HA via demineralization and remineralization. This mineral exchange mechanism provides the opportunity to introduce $\mathrm{F}^{-}$deep in the enamel structure to form FA. Forming FA deep in the mineral component of the rod sheath has important physiologic implications. FA in the inter-rod substance may be the reason that acid etching procedures show that the rod sheath is usually more resistant to demineralization (Fig. 1) [101, 102]. The clinical benefit for this aspect of differential etching is the type 1 etching pattern with deep surface recesses which is favorable for bonding to enamel. The unfavorable type 3 etching pattern (relatively flat surface) may reflect a patient history of inadequate exposure to $\mathrm{F}^{-}$. Furthermore, the retained rod sheath after the rods are demineralized provides a substrate for remineralization of the 
superficial enamel layer which explains the mechanism for producing a WSL. A history of adequate $\mathrm{F}^{-}$to produce FA by remineralization deep in the rod sheath mineral fraction may differentiate enamel surfaces predisposed to WSLs rather than cavitated caries. Thus, WSLs are characteristic of plaquecoated smooth enamel surfaces $[88,89,96,103]$. However, demineralization-resistant inter-rod substance of subjects with a history of $\mathrm{F}^{-}$exposure may be an important aspect of the specific pathogenesis [1]. Furthermore, enamel is an anisotropic material with a tough network of interconnected fibrous tissue, i.e., inter crystalline substance or matrix [104]. Similar to bone, enamel can maintain its structural integrity despite considerable internal porosity $[53,54 \bullet, 55 \bullet]$.

When the demineralization process associated with the action of plaque acid overwhelms the balancing remineralization capability of saliva and hygiene, caries is active, and there is a net loss of tooth mineral over time (Fig. 1) [103]. For over 50 years, it has been known that early (incipient) caries are not clinically perceptible, but the lesions within enamel can be detected with histologic sections [54•]. Active caries progressively increases the depth of the demineralized zone in the direction of the DEJ. Once the subsurface zone of enamel porosity reaches a depth of about $400 \mu \mathrm{m}$, air drying of the enamel surface for $\sim 5 \mathrm{~s}$ reveals a visually perceptible white spot lesion [54 , 77]. The width of the subsurface demineralized zone (Fig. 2) increases light scattering [57, 105] which disrupts the normally anisotropic translucence of enamel [106]. It is important to reemphasize in this context the lack of a reliable clinical procedure to detect and assess invisible subsurface carious lesions. This problem has been recognized for some time in restorative dentistry. Considerable research and development is focused on determining which white spots and invisible subsurface lesions are sites of active caries because no treatment is indicated for inactive lesions $[107,108]$. On the other hand, for orthodontics, it is important to detect and manage all subsurface enamel demineralizations prior to bonding fixed appliances. The rapid deterioration of susceptible patients with labial $[54 \cdot, 59,89]$ and to a lesser extend lingual [109] appliances suggests a heavy plaque load associated with poor hygiene potentiates active lesions and reestablishes active caries in previously inactive sites. In contrast to restorative dentistry, orthodontics requires a comprehensive method for detecting and managing all subsurface demineralizations.

Invisible caries is defined as protected (subsurface) decalcified sites $(<400 \mu \mathrm{m}$ deep) that are resistant to mechanical abrasion, dental hygiene, or professional prophylaxis (Fig. 1) $[82,96]$. Polishing enamel surfaces with pumice prior to bonding orthodontic appliances removes both plaque and the protective proteins of the salivary pellicle. Noncavitated WSLs ( $>400 \mu \mathrm{m}$ deep) can occur within 4 weeks in a defined, plaque-filled space under an orthodontic band [54•,55•]. Routine follow-up of active treatment patients may document extensive WSLs within 12months after bonding brackets [89]; but particularly susceptible patients are affected in only 3 6 month. It is hypothesized that high-risk patients had undetected subsurface lesions prior to the start of treatment. Retained plaque around orthodontic brackets accelerates active caries and reinoculates previously inactive lesions. Patients with poor hygiene and a carbohydrate-rich diet may experience WSLs within weeks after the start of active treatment [54•].

Orthodontically induced WSLs are a major problem worldwide $[54 \cdot, 59,89,109]$. It is not only an esthetic issue because WSLs may progress to serious cavitated caries during or after active treatment [89]. Distinguishing active from inactive lesions is a valid strategy for restorative dentistry, but all enamel surfaces damaged by caries are a concern for orthodontics because caries can be reinoculated by retained plaque. Effective pretreatment and progress screening of orthodontics patients is critical for the management of invisible caries prior to forming WSLs. Multiple new technologies are available or are in development for detecting incipient caries: fiber-optic trans-illumination, quantitative light-induced fluorescence (QLF), digital image fiber-optic trans-illumination, electrical conductance measurement, digital subtraction radiography, laser fluorescence measurement, and ultrasound caries detection [97]. In addition, optical coherence tomography systems are effective for noninvasive assessment of hard dental tissues $[72,98]$. The emphasis for most new device development is on pits, fissures, and interproximal caries [99]. None of the physical methods currently available are capable of detecting shallow $(<400 \mu \mathrm{m}$ deep), invisible lesions on smooth enamel surfaces.

A safe, rapid, and reliable method for detecting early invisible carious lesions is badly needed. If teeth with compromised enamel are detected prior to bonding fixed appliances, pretreatment preventative and repair procedures can be accomplished prior to bonding fixed appliances. Orthodontics with fixed appliances on labial surfaces is a concern for patients predisposed to smooth surface caries because the enamel is relatively thin in the cervical area gingival to the bonded brackets [1]. Cavitated caries can rapidly penetrate the pulp. In addition, a simple method with adequate sensitivity for detecting invisible caries would be very useful during orthodontic treatment to monitor high-risk zones. Early detection of invisible lesions is critical for the timely intervention with preventive and corrective measures to avoid WSLs. For some uncooperative patients, discontinuing elective treatment may be indicated.

\section{Emerging Technologies}

Three emerging technologies show promise. First, the CALCIVIS ${ }^{\circledR}$ Imaging System employs a bioluminescence 
technology to detect free calcium ions emitted by active carious lesions [107]. This system measures the level of caries activity [108], as a function of free calcium ions within WSLs, but it is "not a caries detection device." [107] The application of CALCIVIS $®$ for detecting and managing clinically invisible incipient lesions $(<400 \mu \mathrm{m})$ has not been demonstrated. Second, cationic fluorescein-labeled starch nanoparticles have been developed in vitro for the assessment of caries activity [110]. This system may prove useful for detecting active subsurface caries, but it does not appear suitable for detecting all incipient lesions in the enamel. Thus, the method is not suitable for the thorough enamel evaluation required prior to orthodontics. Finally, a group in Australia with extensive experience in molar-incisor hypomineralization [111-113] developed a hydroxyapatite-binding porosity probe based on bovine hemoglobin that shows promise for detecting shallow subsurface carious lesions down to depth of $\sim 30$ microns [114]. Colorimetric detection of invisible lesions is via HA-binding proteins coupled to intensely colored dyes. The technology is relatively simple, safe, and intuitive for a dentist in a routine clinical setting, so it shows promise for both early detection and activity monitoring.

Collectively, these emerging technologies provide a perspective for detection and assessment of early-stage carious lesions. All the technologies require approval for use in human subjects as well as clinical validation for sensitivity and specificity. For orthodontic purposes, it is important to disclose all subsurface porosity and then attempt to remineralize it prior to orthodontic treatment. Periodic evaluation during active treatment should emphasize detection of active carious lesions on all exposed enamel surfaces.

\section{Treatment of WSLs}

Prevention is the most effective and efficient management for WSLs. Pretreatment education and motivational training in oral hygiene procedures with a $\mathrm{F}^{-}$containing toothpaste and diet control are indicated prior to elective treatment such as extensive restorations or orthodontics with fixed appliances [96]. Reasonable adherence to plaque and diet control is usually all that is needed to prevent decalcifications and caries. However, some potential patients fail to comply, and continued emphasis on preventative measures is counterproductive. A common scenario is parents who are motivated for treatment of their children who are not motivated and may even be defiant. Marginal or poor compliance with diet and/or hygiene by a potential patient is a contraindication for elective treatment $[58,89]$. In the absence of an effective diagnostic test for invisible caries, a plaque index is currently the best indicator for patients at high risk for WSLs. If a patient fails to demonstrate adequate plaque control, extensive restorative dentistry or fixed orthodontic appliances are contraindicated. For resolving malocclusion for patients with questionable hygiene, it may be appropriate to pursue limited treatment with lingual arches, removable appliances, or aligners $[93,94]$. If plaque retention and gingivitis are noted during recall visits, additional brushing instructions and plaque control technology such as chlorhexidine, microtome dynamics, and photodynamic therapy may be needed $[49,73]$. Archwires can be removed to allow better access for hygiene. When WSLs are noted, that is a clear indication that plaque control is inadequate. It is best to discontinue high-risk treatment and pursue other options rather than seriously damage the dentition [89, 96].

The importance of $\mathrm{F}^{-}$for preventing WSLs has resulted in numerous products: mouthwash, gels, toothpaste, varnishes, bracket bonding agents, and elastomers [74-76, 88, 96]. $\mathrm{F}^{-}$ can control caries by inhibitory effects on cariogenic microbes which may result in an arrest of the active caries process. Moderate amounts of $\mathrm{F}^{-}$are effective for remineralization. For an optimal fluoride effect, mouth washes and toothpastes should be applied daily. Fluoride varnishes require application from 2 to 4 times per year [96]. Enamel sealing resin as well as bracket bonding materials and elastomers that release $\mathrm{F}^{-}$have been less successful because there is an inadequate release of $\mathrm{F}^{-}$and/or the mechanical properties of the materials are compromised.

In the absence of cavitation, WSLs are potentially reversible $[4,5]$. Natural remineralization with salivary ions is the preferred method for resolving WSLs. The first step for this approach is to establish good oral hygiene and provide regular professional prophylaxis at 3-6-month intervals. With good plaque and diet control, the carious lesion at the base of a WSL is deprived of nourishment, so the lesion is arrested $[83,108]$. Then $\mathrm{Ca}^{++}$and $\mathrm{PO}_{4}{ }^{3-}$ from the saliva can penetrate through pores in the enamel veneer to remineralize a WSL. Modest daily exposure to $\mathrm{F}^{-}$is advantageous. It is important to avoid large accumulative doses of $\mathrm{F}^{-}$with topical application, rinses, toothpaste, mouthwash, gels, and/or varnish. Forming a dense, less porous layer of FA along the surface enamel may decreases the flow of $\mathrm{Ca}^{++}$and $\mathrm{PO}_{4}{ }^{3-}$ to the subsurface WSL. Tooth bleaching whitens the teeth and thereby masks WSLs [115], but there is no effect on remineralization $[116,117]$. Overall, correction of WSLs is a challenging clinical problem because the rigorous hygiene required is unrealistic for most patients with a history of poor compliance.

Casein derivatives were developed to penetrate the enamel barrier and increase the supply of $\mathrm{Ca}^{++}$and $\mathrm{PO}_{4}{ }^{3-}$ to enhance remineralization [116, 117]. Casein phosphopeptidesamorphous calcium phosphate (CPP-ACP) is a mineralization agent produced from milk that helps ameliorate WSLs. $\mathrm{F}^{-}$is a helpful adjunct in modest amounts, so it is added to the casein remineralization paste and dental varnish. These products are popular in clinical practice, and many offices provide the paste 
at no additional fee. That may be a wise strategy for limiting liability in refractory patients. However, routine remineralization of WSLs remains elusive. A systematic review published in 2016, reported good oral hygiene with high-fluoride tooth paste, is comparable in effectiveness to $\mathrm{F}^{-}$supplemented casein derivatives for prevention of new WSLs [96]. For treatment of WSLs, neither MI Paste Plus ${ }^{\circledR}$ (GC America, Alsip, Ill) nor PreviDent ${ }^{\circledR}$ (Colgate Oral Pharmaceuticals, New York, NY) $\mathrm{F}^{-}$varnish was more effective than routine oral hygiene procedures for improving WSLs in an 8-week clinical trial after orthodontic treatment [118].

Preventing WSLs is best accomplished with a careful history. Children may have been treated with nonsurgical caries management techniques [119-121], so the risk of decalcifications may not be obvious. Lack of active caries does not preclude inactive enamel lesions that can be reinoculated due to inadequate oral hygiene measures. If prevention fails, all the restorative measures for correcting WSLs have limitations. Resin infiltration improves enamel esthetics but does not remove WSLs [122]. The most reliable restorative procedure for removing WSLs is microabrasion to remove the outer enamel barrier to allow the internal decalcification to remineralize with salivary ions [123]. Fluoride supplemented, casein derivative paste may be more effective after microabrasion because the enamel barrier is removed [123, 124]. The obvious concern with microabrasion is the net loss of enamel, but compared to veneer restorations, it is considerably more conservative, cost-effective, and less prone to long-term problems [125-127].

\section{Removable Lingual Arch}

Enamel decalcifications have been a risk in orthodontics since the initiation of modern fixed appliances in the early twentieth century [128-130]. The generalized decalcification tendency long noted with banded appliances is exacerbated by loose bands as well as exposed enamel between the inferior border of a band and the gingival margin. Gorelick et al. (1982) [131] coined the term "white spots" to define the orthodontic lesions that are characteristic for both banded and bonded teeth. WSLs are very common for bonded brackets (prevalence $>36 \%$ in patients with poor hygiene and a cariogenic diet) [89]. Dr. John Valentine Mershon (1867-1953) was a 1908 graduate of the Angle School of Orthodontia. He trained in an era when heavy forces to move teeth were applied to the labial surfaces of the dentition [132]. Dr. Mershon was concerned that large applied loads were not physiologic, so he invented or at least popularized the use of a removable lingual arch (RLA). A RLA is readily adjustable to "gently nudge teeth into more desired positions." An important serendipitous benefit of the appliance is that it is much less prone to plaque retention. Decalcifications have not been reported for the lingual surfaces of teeth treated with labial appliances [89, 131]. Thus, a RLA is largely plaque free, and it applies forces on the self-cleansing lingual surfaces [109], so decalcification is unlikely.

Use of bonded brackets during mixed dentition treatment is associated with long treatment times, compromised outcomes, and serious enamel decalcifications [89, 133]. Control of decalcifications (WSLs) was not a stated goal for Dr. Mershon, but it is important to note that there are no decalcification reports associated with the use RLAs in over a century of use. The RLA is useful for maintaining and correcting arch widths during active treatment $[134,135]$. In addition, RLAs have proven to be particularly efficient for mixed dentition treatment in the lower arch. They are effective for space management, arch development, and alignment during the juvenile years. The only appreciable risk for decalcification is loose bands on the first molars. When using RLAs for lengthy mixed dentition treatment, it is important to utilize glass ionomer cement for first molar bands, ask the patient and parent to regularly monitor band retention, and clinically test band retention at each treatment visit. A RLA is very efficient for low-risk mixed dentition treatment for class I crowded malocclusions [136], but it is also useful for class II (retrognathic) malocclusions [137]. Compared to labial fixed appliances, RLA treatment presents much less risk for iatrogenic decalcifications and WSLs [59, 89, 96, 131].

\section{Conclusions}

WSLs are mineralized tissue pathophysiology that is often obscure to clinicians. Understanding the etiology, progression, arrest, and remineralization of WSLs is crucial for ideal orthodontic practice. Efficient WSL management begins with patients demonstrating good oral hygiene and fluoridated toothpaste before starting elective treatment. The physiologic rationale is that teeth are perfused with ion-rich fluid from the saliva which is capable of substituting $\mathrm{F}^{-}$deep into the HA structure to resist demineralization. During active treatment, hygiene with fluoridated toothpaste should be enforced at each appointment. If WSLs are detected, the braces should be removed as soon as possible to initiate a follow-up remineralization program that focuses on plaque control with a fluoridated toothpaste. It is important to avoid excessive $\mathrm{F}^{-}$during remineralization because a very dense enamel veneer on a WSL can inhibit the percolation of calcium and phosphate ions into the subsurface lesion. To prevent WSLs, there is a glaring need for a simple clinical technology to detect shallow invisible caries. Remineralization procedures prior to orthodontic treatment and effective monitoring of enamel deterioration during treatment would greatly enhance the clinical prevention and control of WSLs. 
Acknowledgements The senior author (WER) would like to thank the President of the American Association Dr. Christopher Roberts and program consultant Dr. James McNamara for selecting him as the 2021 Dr. John Valentine Mershon Lecturer. This review of literature was presented at the 2021 Annual Meeting of the American Association of Orthodontists. In addition, WER is indebted to coauthor Paul M. Schneider, former Chairman of Orthodontics at the University of Melbourne, for focusing on the impact of dental demineralization (MIH and white spots) on malocclusion, health, and wellness.

Funding Open Access funding enabled and organized by CAUL and its Member Institutions.

\section{Compliance with Ethical Standards}

Conflict of Interest W. Eugene Roberts and Paul Schneider declare no conflict of interest.

Jonathan Magnum reports a grant, personal fees as an employee, and owning shares of Incisive Technologies, and has a patent issued (WO2011/113107A1).

Human and Animal Rights and Informed Consent This article does not contain any studies with human or animal subjects performed by any of the authors.

Open Access This article is licensed under a Creative Commons Attribution 4.0 International License, which permits use, sharing, adaptation, distribution and reproduction in any medium or format, as long as you give appropriate credit to the original author(s) and the source, provide a link to the Creative Commons licence, and indicate if changes were made. The images or other third party material in this article are included in the article's Creative Commons licence, unless indicated otherwise in a credit line to the material. If material is not included in the article's Creative Commons licence and your intended use is not permitted by statutory regulation or exceeds the permitted use, you will need to obtain permission directly from the copyright holder. To view a copy of this licence, visit http://creativecommons.org/licenses/by/4.0/.

\section{References}

Papers of particular interest, published recently, have been highlighted as:

- Of importance

1. Roberts WE, Mangum JE, Schneider PM. Pathophysiology of demineralization, part I: attrition, erosion, abfraction, and noncarious cervical lesions. 2021. https://doi.org/10.1007/ s11914-022-00722-1

2. Roberts WE, Roberts JA, Epker BN, Burr DB, Hartsfield Jr JK. Remodeling of mineralized tissues, part I: the Frost legacy. Sem Orthod 1 2006;2(4):216-23.

3. Roberts WE, Roberts JA, Epker BN, Burr DB, Hartsfield Jr JK. Remodeling of mineralized tissues, part II: control and pathophysiology. Sem Orthod 2006;12(4):238-253, Dec

4. Featherstone JD. The caries balance: contributing factors and early detection. J Calif Dent Assoc. 2003;31(2):129-33.

5. Featherstone J. The continuum of dental caries - evidence for a dynamic disease process. J Dent Res. 2004;83:C39-42. https:// doi.org/10.1177/154405910408301s08.
6. Hicks J, Garcia-Godoy F, Flaitz C. Biological factors in dental caries: role of saliva and dental plaque in the dynamic process of demineralization and remineralization (part 1). J Clin Pediatr Dent. 2003;28(1):47-52.

7. Hicks J, Garcia-Godoy F, Flaitz C. Biological factors in dental caries enamel structure and the caries process in the dynamic process of demineralization and remineralization (part 2). J Clin Pediatr Dent. 2004;28(2):119-24.

8. Hicks J, Garcia-Godoy F, Flaitz C. Biological factors in dental caries: role of remineralization and fluoride in the dynamic process of demineralization and remineralization (part 3). J Clin Pediatr Dent. 2004;28(3):203-14.

9. Eick S. Biofilms. Monogr Oral Sci. 2021;29:1-11.

10. Junka A, Szymczyk P, Ziółkowski G, Karuga-Kuzniewska E, Smutnicka D, Bil-Lula I, Bartoszewicz M, Mahabady S, Sedghizadeh PP. Bad to the bone: on in vitro and ex vivo microbial biofilm ability to directly destroy colonized bone surfaces without participation of host immunity or osteoclastogenesis. PLoS One. 2017;12(1):e0169565.

11. Kapellas K, Roberts-Thomson KF. National study of adult oral health 2017-18: root caries. Aust Dent J. 2020;65(Suppl 1):S40-6.

12. Elhennawy K, Finke C, Paris S, Reda S, Jost-Brinkmann PG, Schwendicke F. Selective vs stepwise removal of deep carious lesions in primary molars: 24 months follow-up from a randomized controlled trial. Clin Oral Investig. 2020;25:645-52. https:// doi.org/10.1007/s00784-020-03536-6. Epub ahead of print.

13. Lin Y, Su J, Wang Y, Xu D, Zhang X, Yu B. mRNA transcriptome analysis of bone in a mouse model of implantassociated Staphylococcus aureus osteomyelitis. Infect Immun. 2021;22:IAI.00814-20. https://doi.org/10.1128/IAI.00814-20 Epub ahead of print.

14. Chinnadurai S, Chilukuri B, Mahendran B, Mantharam V, Selvakumar B, Sankaralingam R. Clinical profile of osteonecrosis in systemic lupus erythematosus - experience from a tertiary care centre in South India. J Family Med Prim Care. 2020;9(8):43637.

15. Leknes KN. The influence of anatomic and iatrogenic root surface characteristics on bacterial colonization and periodontal destruction: a review. J Periodontol. 1997;68(6):507-16.

16. Thurnheer T, Paqué PN. Biofilm models to study the etiology and pathogenesis of oral diseases. Monogr Oral Sci. 2021;29:30-7.

17. Babaeekhou L, Mehrizi AA, Ghane M. Streptococcus mutans, sugar consumption, and oral hygiene: which one has more effect on decayed, missing, and filled teeth (DMFT) score in Iranian adults? Dent Res J (Isfahan). 2020;17(2):134-41.

18. Niu JY, Yin IX, Wu WKK, Li QL, Mei ML, Chu CH. Antimicrobial peptides for the prevention and treatment of dental caries: a concise review. Arch Oral Biol. 2020;122:105022. https://doi.org/10.1016/j.archoralbio.2020.105022 Epub ahead of print.

19. Merglova V, Koberova-Ivancakova R, Broukal Z, Dort J. The presence of cariogenic and periodontal pathogens in the oral cavity of one-year-old infants delivered pre-term with very low birthweights: a case control study. BMC Oral Health. 2014;14:109.

20. Bratton TA, Jackson DC, Nkungula-Howlett T, Williams CW, Bennett CR. Management of complex multi-space odontogenic infections. J Tenn Dent Assoc. 2002;82(3):39-47.

21. Gupta M, Singh V. A retrospective study of 256 patients with space infection. J Maxillofac Oral Surg. 2010;9(1):35-7. This is a large clinical evaluation of body space infections due to fistulas from abcessed teeth that were devitalized by caries. Even with modern treatment these body space infections are potentially fatal.

22. Lin QL, Du HL, Xiong HY, Li B, Liu J, Xing XH. Characteristics and outcomes of Ludwig's angina in patients admitted to the 
intensive care unit: a 6-year retrospective study of 29 patients. J Dent Sci. 2020;15(4):445-50.

23. Justiz Vaillant AA, Qurie A. Immunodeficiency. 2020 Dec 30. In: StatPearls [Internet]. Treasure Island (FL): StatPearls Publishing; 2021 Jan-.

24. Haque M, Sartelli M, Haque SZ. Dental infection and resistanceglobal health consequences. Dent J (Basel). 2019;7(1):22 Published 2019 Mar 1.

25. Sen S, Redd K, Trivedi T, Moss K, Alonso A, Soliman EZ, Magnani JW, Chen LY, Gottesman RF, Rosamond W, Beck J, Offenbacher S. Periodontal disease, atrial fibrillation and stroke. Am Heart J. 2021;24:S0002-8703(21)00013-2. https://doi.org/ 10.1016/j.ahj.2021.01.009 Epub ahead of print.

26. Mosen D, Pihlstrom D, Snyder J, Smith N, Shuster E, Rust K. Association of dental care with adherence to HEDIS measures. Perm J. 2016;20(1):33-40.

27. Roberts WE, Huja SS, Roberts JA. Bone modeling: biomechanics, molecular mechanisms and clinical perspectives. Semin Orthod. 2004;10(2):123-61.

28. Meema HE, Oreopoulos DG, Meema S. A roentgenologic study of cortical bone resorption in chronic renal failure. Radiology. 1978;126(1):67-74.

29. Al-Obaidi R, Salehi H, Desoutter A. Chemical \& nanomechanical study of artificial human enamel subsurface lesions. Sci Rep. 2018;8(1):4047. The importance of this study is the use of noninvasive technology (raman microscopy) to define the detailed structure of subsurface white spot lesions within intact enamel.

30. Schilcher J, Bernhardsson M, Aspenberg P. Chronic anterior tibial stress fractures in athletes: no crack but intense remodeling. Scand J Med Sci Sports. 2019;29(10):1521-8.

31. Dincer O, Kose TE, Cankaya AB, Aybar B. Traumatic bone cyst mimicking radicular cyst. BMJ Case Rep. 2012;2012: bcr2012007316 Published 2012 Dec 9.

32. Wigsten E. Jonasson P; EndoReCo, Kvist T. Indications for root canal treatment in a Swedish county dental service: patient- and tooth-specific characteristics. Int Endod J. 2019;52(2):158-68.

33. Kwon T, Lamster IB, Levin L. Current concepts in the management of periodontitis. Int Dent J. 2020;71:462-76. https://doi.org/ 10.1111/idj.12630. Epub ahead of print.

34. Brennan-Calanan RM, Genco RJ, Wilding GE, Hovey KM, Trevisan M, Wactawski-Wende J. Osteoporosis and oral infection: independent risk factors for oral bone loss. J Dent Res. 2008;87(4):323-7.

35. Ogle OE. Odontogenic Infections. Dent Clin N Am. 2017;61(2): 235-52.

36. Milstrey A, Rosslenbroich S, Everding J, Raschke MJ, Richards RG, Moriarty TF, Puetzler J. Antibiofilm efficacy of focused highenergy extracorporeal shockwaves and antibiotics in vitro. Bone Joint Res. 2021;10(1):77-84.

37. Baldan R, Sendi P. Precision medicine in the diagnosis and management of orthopedic biofilm infections. Front Med (Lausanne). 2020;10(7):580671.

38. Lusche I, Dirk C, Frentzen M, Meister J. Cavity disinfection with a $445 \mathrm{~nm}$ diode laser within the scope of restorative therapy - a pilot study. J Lasers Med Sci. 2020;11(4):417-26.

39. Preusse PJ, Winter J, Amend S, Roggendorf MJ, Dudek MC, Krämer N, Frankenberger R. Class II resin composite restorations-tunnel vs. box-only in vitro and in vivo. Clin Oral Investig. 2021;25(2):737-44.

40. Huchital MJ, Saleh A, Patel R, Subik M. Cancelloplasty for Treatment of osteomyelitis of the calcaneus: a novel technique and case report. Foot Ankle Spec. 2020;3:1938640020975885265. https://doi.org/10.1177/1938640020975885. Epub ahead of print.
41. Chazel JC, Tramini P, Valcarcel J, Pélissier B. A comparative analysis of periapical health based on historic and current data. Int Endod J. 2005;38(5):277-84.

42. Brauns A, Lammens J. The challenge of the infected pilon tibial non-union: treatment with radical resection, bone transport and ankle arthrodesis. Acta Orthop Belg. 2020;86(2):335-41.

43. Yang X, Ye AY, Katebi N, Volloch V, Khullar SM, Patel V, Olsen BR. Mycobacterial and plasmodium ovale-associated destruction of the jaw bones. Oral Dis. 2020. https://doi.org/10.1111/ odi.13756 Epub ahead of print.

44. Musso N, Caruso G, Bongiorno D, Grasso M, Bivona DA, Campanile F, Caraci F, Stefani S. Different modulatory effects of four methicillin-resistant Staphylococcus aureus clones on MG-63 osteoblast-like cells. Biomolecules. 2021;11(1):E72.

45. Kim JE, Yoo S, Choi SC. Several issues regarding the diagnostic imaging of medication-related osteonecrosis of the jaw. Imaging Sci Dent. 2020;50(4):273-9.

46. Woolley J, Akintola O, Yates J, Calasans-Maia MD, de Albuquerque C-MJ, Kocherhina I, Sacco R. The risk of osteonecrosis of the jaw and adverse outcomes in patients using antiresorptive drugs undergoing orthodontic treatment: a systematic review. Heliyon. 2021;7(1):e05914. https://doi.org/10.1016/j. heliyon.2021.e05914 PMID: 33490677; PMCID: PMC7810783.

47. Veith PD, Gorasia DG, Reynolds EC. Towards defining the outer membrane proteome of Porphyromonas gingivalis. Mol Oral Microbiol. 2020;36:25-36. https://doi.org/10.1111/omi.12320. Epub ahead of print.

48. Wang Q, Ma JB, Wang B, Zhang X, Yin YL, Bai H. Alterations of the oral microbiome in patients treated with the Invisalign system or with fixed appliances. Am J Orthod Dentofac Orthop. 2019;156(5):633-40.

49. Kado I, Hisatsune J, Tsuruda K, Tanimoto K, Sugai M. The impact of fixed orthodontic appliances on oral microbiome dynamics in Japanese patients. Sci Rep. 2020;10(1):21989.

50. Guo R, Zheng Y, Zhang L, Shi J, Li W. Salivary microbiome and periodontal status of patients with periodontitis during the initial stage of orthodontic treatment. Am J Orthod Dentofac Orthop. 2021;S0889-5406(21):00052-4. https://doi.org/10.1016/j.ajodo. 2019.11.026 Epub ahead of print.

51. Müller LK, Jungbauer G, Jungbauer R, Wolf M, Deschner J. Biofilm and orthodontic therapy. Monogr Oral Sci. 2021;29: 201-13.

52. Papadimitriou A, Kouvelis G, Fanaropoulou T, Doulis I, Kyriakoula M, Mparmpouni A, Kloukos D. Effects of selfligating orthodontic appliances on the periodontal health of adolescents: a prospective cohort study. Oral Health Prev Dent. 2021;19(1):129-35.

53. Silverstone LM. Structure of carious enamel, including the early lesion. Oral Sci Rev. 1973;3:100-60.

54. Holmen L, Thylstrup A, Ogaard B, Kragh F. A polarized light microscopic study of progressive stages of enamel caries in vivo. Caries Res. 1985;19(4):348-54. This is a classic clinical study utilizing polarized microscopy to define the progressive stages involved in white spot formation due to natural caries that occurs under an orthodontic band.

55. Holmen L, Thylstrup A, Ogaard B, Kragh F. A scanning electron microscopic study of progressive stages of enamel caries in vivo. Caries Res. 1985;19(4):355-67. This companion study for reference 54 describes enamel physiology as well as pathophysiology for caries formation of white spot lesions in enamel under similar defined clinical conditions. The coordinated use of polarized light and scanning microscopy is the first realistic description of the disease process to produce white spot lesions. 
56. Warshawsky H, Josephsen K, Thylstrup A, Fejerskov O. The development of enamel structure in rat incisors as compared to the teeth of monkey and man. Anat Rec. 1981;200(4):371-99.

57. Darling CL, Huynh GD, Fried D. Light scattering properties of natural and artificially demineralized dental enamel at $1310 \mathrm{~nm}$. J Biomed Opt. 2006;11(3):34023.

58. McKeever A. Management of white spot lesions. Masters Thesis in Orthodontics, University of Melbourne, Melbourne, Australia, 2017.

59. Khoroushi M, Kachuie M. Prevention and treatment of white spot lesions in orthodontic patients. Contemp Clin Dent. 2017;8(1):119 .

60. Tahmassebi JF, BaniHani A. Impact of soft drinks to health and economy: a critical review. Eur Arch Paediatr Dent. 2020;21(1): $109-17$

61. Costacurta M, DiRenzo L, Sicuro L, Gratteri S, De Lorenzo A, Docimo R. Dental caries and childhood obesity: analysis of food intakes, lifestyle. Eur J Paediatr Dent. 2014;15(4):343-8.

62. Signori C, Maske TT, Digmayer Romero VH, Cenci MS. Influence of biofilm removal from the tooth-restoration interface on the progression of secondary caries lesions: a preliminary in vitro model study. Biofouling. 2020;36(10):1272-83.

63. Kassebaum NJ, Bernabé E, Dahiya M, Bhandari B, Murray CJ, Marcenes W. Global burden of untreated caries: a systematic review and metaregression. J Dent Res. 2015;94(5):650-8.

64. Lussi A, Jaeggi T, Zero D. The role of diet in the aetiology of dental erosion. Caries Res. 2004;38(Suppl 1):34-44.

65. Cossa F, Piastra A, Sarrion-Pérez MG, Bagán L. Oral manifestations in drug users: a review. J Clin Exp Dent. 2020;12(2):e193200.

66. Delgado A, Dias Ribeiro AP, Aslam M, Olafsson VG, Pereira PN. Erosive assessment of dry mouth lozenges and tablets on enamel and dentin. J Dent. 2020;105:103496.

67. Delgado AJ, Dias Ribeiro AP, Quesada A, Rodríguez LE, Hernández R, Wynkoop B, Dilbone DA. Potential erosive effect of mouth rinses on enamel and dentin. Gen Dent. 2018;66(3):759 .

68. Dental Caries in Adults (Age 20 to 64) $\mid$ Data \& Statistics ... www. nidcr.nih.gov/research/data-statistics/dental-caries/adults, sourced December 28, 2020.

69. Listl S, Galloway J, Mossey PA, Marcenes W. Global economic impact of dental diseases. J Dent Res 2016. 2015;94(10):1355-61.

70. Steiger-Ronay V, Kuster IM, Wiedemeier DB, Attin T, Wegehaupt FJ. Erosive loss of tooth substance is dependent on enamel surface structure and presence of pellicle - an in vitro study. Arch Oral Biol. 2020;112:104686.

71. Tektas S, Thurnheer T, Eliades T, Attin T, Karygianni L. Initial bacterial adhesion and biofilm formation on aligner materials. Antibiotics (Basel). 2020;9(12):908.

72. Şen S, Erber R, Deurer N, Orhan G, Lux CJ, Zingler S. Demineralization detection in orthodontics using an ophthalmic optical coherence tomography device equipped with a multicolor fluorescence module. Clin Oral Investig. 2020;24(8):2579-90.

73. Gómez C, Abellán R, Palma JC. Efficacy of photodynamic therapy vs ultrasonic scaler for preventing gingival inflammation and white spot lesions during orthodontic treatment. Photodiagn Photodyn Ther. 2018;24:377-83.

74. Alexandria AK, Nassur C, Nóbrega CBC, Branco-de-Almeida LS, Dos Santos KRN, Vieira AR, Neves AA, Rosalen PL, Valença AMG, Maia LC. Effect of TiF4 varnish on microbiological changes and caries prevention: in situ and in vivo models. Clin Oral Investig. 2019;23(6):2583-91.

75. Kitasako Y, Sadr A, Hamba H, Ikeda M, Tagami J. Gum containing calcium fluoride reinforces enamel subsurface lesions in situ. J Dent Res. 2012;91(4):370-5.
76. Mascarenhas AK. Is fluoride varnish safe?: Validating the safety of fluoride varnish. J Am Dent Assoc. 2021;152(5):364-8.

77. Ismail AI, Sohn W, Tellez M, Amaya A, Sen A, Hasson H, Pitts NB. The International Caries Detection and Assessment System (ICDAS): an integrated system for measuring dental caries. Community Dent Oral Epidemiol. 2007;35(3):170-8.

78. Young DA, Nový BB, Zeller GG, Hale R, Hart TC, Truelove EL. American Dental Association Council on Scientific Affairs; American Dental Association Council on Scientific Affairs. The American Dental Association Caries Classification System for clinical practice: a report of the American Dental Association Council on Scientific Affairs. J Am Dent Assoc. 2015;146(2): 79-86.

79. Roberts WE, Huja SS. Bone physiology, metabolism, and biomechanics in orthodontic practice. In: Graber LW, Vanarsdall RL, Vig KWL, Huang GJ, editors. Orthodontics: current principles and techniques. 6th ed. Elsevier: St. Louis; 2017. p. 99-152.

80. Austin D, JayaKumar HL, Chandra KM, Kemparaj V, Prahladka P. Cross-sectional study on white spot lesions and its association with dental caries experience among school children. Int J Clin Pediatr Dent. 2020;13(2):107-12.

81. Ilie O, van Turnhout AG, van Loosdrecht MC, Picioreanu C. Numerical modeling of tooth enamel subsurface lesion formation induced by dental plaque. Caries Res. 2014;48(1):73-89.

82. Chan KH, Tom H, Lee RC, Kang H, Simon JC, Staninec M, Darling CL, Pelzner RB, Fried D. Clinical monitoring of smooth surface enamel lesions using CP-OCT during nonsurgical intervention. Lasers Surg Med. 2016;48(10):915-23.

83. Nyvad B, Machiulskiene V, Baelum V. Reliability of a new caries diagnostic system differentiating between active and inactive caries lesions. Caries Res. 1999;33(4):252-60.

84. Park KJ, Voigt A, Schneider H, Ziebolz D, Haak R. Light-based diagnostic methods for the in vivo assessment of initial caries lesions: laser fluorescence. QLF and OCT Photodiagnosis Photodyn Ther. 2021;34:102270. https://doi.org/10.1016/j.pdpdt. 2021.102270 Epub ahead of print.

85. Gao SS, Zhao IS, Duffin S, Duangthip D, Lo ECM, Chu CH. Revitalising silver nitrate for caries management. Int J Environ Res Public Health. 2018;15(1):80.

86. Gao SS, Duangthip D, Wong MCM, Lo ECM, Chu CH. Randomized trial of silver nitrate with sodium fluoride for caries arrest. JDR Clin Trans Res. 2019;4(2):126-34. https://doi.org/10. 1177/2380084418818482 Epub 2019 Feb 15.

87. Crystal YO, Niederman R. Evidence-based dentistry update on silver diamine fluoride. Dent Clin N Am. 2019;63(1):45-68.

88. Dental Decay. Wikipedia sourced January 16, 2021.

89. Chapman JA, Roberts WE, Eckert GJ, Kula KS, GonzálezCabezas C. Risk factors for incidence and severity of white spot lesions during treatment with fixed orthodontic appliances. Am J Orthod Dentofac Orthop. 2010;138(2):188-94.

90. Komiya R, Wada T, Tsushima F, Sakamoto K, Ikeda T, Yamaguchi A, Harada H, Uo M. Quantitation and distribution of metallic elements in sequestra of medication-related osteonecrosis of jaw (MRONJ) using inductively coupled plasma atomic emission spectroscopy and synchrotron radiation X-ray fluorescence analysis. J Bone Miner Metab. 2019;37(4):676-84.

91. Bagan L, Jiménez Y, Leopoldo M, Murillo-Cortes J, Bagan J. Exposed necrotic bone in 183 patients with bisphosphonaterelated osteonecrosis of the jaw: associated clinical characteristics. Med Oral Patol Oral Cir Bucal. 2017;22(5):e582-5.

92. Ragazzo M, Val M, Montagner G, Trojan D, Fusetti S, Guarda NL. Human amniotic membrane: an improvement in the treatment of medication-related osteonecrosis of the jaw (MRONJ)? A casecontrol study. Cell Tissue Bank. 2021; https://doi.org/10.1007/ s10561-021-09922-y. Epub ahead of print. 
93. Alexander SA. The effect of fixed and functional appliances on enamel decalcifications in early Class II treatment. Am J Orthod Dentofac Orthop. 1993;103(1):45-7.

94. Boyd RL. Periodontal and restorative considerations with clear aligner treatment to establish a more favorable restorative environment. Compend Contin Educ Dent. 2009;30(5):280-2, 284, 286-8 passim.

95. Websites sourced January 2021: https://clearsmilecharlotte.com/ blog/how-to-avoid-demineralization-while-using-invisalign/; https://www.azurefamilydental.com/what-is-decalcification-howcan-i-prevent-it/

96. Lapenaite E, Lopatiene K, Ragauskaite A. Prevention and treatment of white spot lesions during and after fixed orthodontic treatment: a systematic literature review. Stomatologija. 2016;18(1):38.

97. Parveen K, Wyne AH. Methods for caries detection: an overview. Pakistan Oral Dent J. 2015;35(4):666-9.

98. Sahyoun CC, Subhash HM, Peru D, Ellwood RP, Pierce MC. An experimental review of optical coherence tomography systems for noninvasive assessment of hard dental tissues. Caries Res. 2020;54(1):43-54.

99. Abogazalah N, Ando M. Alternative methods to visual and radiographic examinations for approximal caries detection. J Oral Sci. 2017;59(3):315-22.

100. Takito J, Inoue S, Nakamura M. The sealing zone in osteoclasts: a self-organized structure on the bone. Int J Mol Sci. 2018;19(4): 984

101. Espinosa R, Valencia R, Uribe M, Ceja I, Saadia M. Enamel deproteinization and its effect on acid etching: an in vitro study. J Clin Pediatr Dent. 2008;33(1):13-9.

102. Valencia R, Espinosa R, Borovoy N, Pérez S, Ceja I, Saadia M. Deproteinization effectiveness on occlusal enamel surfaces and resultant acid etching patterns: an in vitro study. J Clin Pediatr Dent. 2018;42(6):434-41.

103. Selwitz RH, Ismail AI, Pitts NB. Dental caries. Lancet. 2007;369(9555):51-9.

104. White SN, Luo W, Paine ML, Fong H, Sarikaya M, Snead ML. Biological organization of hydroxyapatite crystallites into a fibrous continuum toughens and controls anisotropy in human enamel. J Dent Res. 2001;80(1):321-6.

105. Darling AI. The pathology and prevention of caries. British Dental J. 1959;107(10):287-302.

106. Pitts NB, Zero DT, Marsh PD, Ekstrand K, Weintraub JA, RamosGomez F, Tagami J, Twetman S, Tsakos G, Ismail A. Dental caries. Nat Rev Dis Primers. 2017;3:17030.

107. Pitts N, Shanks N, Longbottom C, Willins M, Vernon B. Clinical validation of a novel bioluminescence imaging technology for aiding the assessment of carious lesion activity status. Clin Exp Dent Res. 2021;7:772-85. https://doi.org/10.1002/cre2.400. Epub ahead of print.

108. Nyvad B, Baelum V. Nyvad criteria for caries lesion activity and severity assessment: a validated approach for clinical management and research. Caries Res. 2018;52(5):397-405.

109. Knösel M, Klang E, Helms HJ, Wiechmann D. Occurrence and severity of enamel decalcification adjacent to bracket bases and sub-bracket lesions during orthodontic treatment with two different lingual appliances. Eur J Orthod. 2016;38(5):485-92.

110. Jones NA, Chang SR, Troske WJ, Clarkson BH, Lahann J. Nanoparticle-based targeting and detection of microcavities. Adv Healthc Mater. 2017;6(1).

111. Schneider PM, Silva M. Endemic molar incisor hypomineralization: a pandemic problem that requires monitoring by the entire health care community. Curr Osteoporos Rep. 2018;16(3):283-8.
112. Mangum JE, Crombie FA, Kilpatrick N, Manton DJ, Hubbard MJ. Surface integrity governs the proteome of hypomineralized enamel. J Dent Res. 2010;89(10):1160-5.

113. Hubbard MJ, Mangum JE, Perez VA, Nervo GJ, Hall RK. Molar hypomineralisation: a call to arms for enamel researchers. Front Physiol. 2017;8:546.

114. Hubbard MJ, Mangum JE. Kit and method for detecting porous dental hydroxyapatite. United States Patent No.: US 10,434,037 B2, October 8, 2019.

115. Choi YY, Lee DY, Kim YJ. Colorimetric evaluation of white spot lesions following external bleaching with fluoridation: an in-vitro study. Korean J Orthod. 2018;48(6):377-383.

116. Reynolds EC. Remineralization of enamel subsurface lesions by casein phosphopeptide-stabilized calcium phosphate solutions. J Dent Res. 1997;76(9):1587-95.

117. Reema SD, Lahiri PK, Roy SS. Review of casein phosphopeptides-amorphous calcium phosphate. Chin J Dent Res. 2014;17(1):7-14.

118. Huang GJ, Roloff-Chiang B, Mills BE, Shalchi S, Spiekerman C, Korpak AM, Starrett JL, Greenlee GM, Drangsholt RJ, Matunas JC. Effectiveness of MI Paste Plus and PreviDent fluoride varnish for treatment of white spot lesions: a randomized controlled trial. Am J Orthod Dentofac Orthop. 2013;143(1):31-41.

119. Augusto MG, da Silva LFO, Scaramucci T, Aoki IV, Torres CRG, Borges AB. Protective effect of anti-erosive solutions enhanced by an aminomethacrylate copolymer. J Dent. 2020;105:103540.

120. Contreras V, Toro MJ, Elías-Boneta AR, Encarnación-Burgos A. Effectiveness of silver diamine fluoride in caries prevention and arrest: a systematic literature review. Gen Dent. 2017;65(3):22-9.

121. Crisp J, Mihas P, Sanders AE, Divaris K, Wright JT. Influences on dentists' adoption of nonsurgical caries management techniques: a qualitative study. J Am Dent Assoc. 2021;152(6):463-70.

122. Prasada KL, Penta PK, Ramya KM. Spectrophotometric evaluation of white spot lesion treatment using novel resin infiltration material (ICON®). J Conserv Dent. 2018;21(5):531-5.

123. Willis GP, Arbuckle GR. Orthodontic decalcification management with microabrasion. J Indiana Dent Assoc. 1992;71(4):16-9.

124. Pini NI, Sundfeld-Neto D, Aguiar FH, Sundfeld RH, Martins LR, Lovadino JR, Lima DA. Enamel microabrasion: an overview of clinical and scientific considerations. World J Clin Cases. 2015;3(1):34-41.

125. Jurado CA, Fischer NG, Mourad F, Villalobos-Tinoco J, Tsujimoto A. Conservative ultrathin veneer restorations with minimal reduction: a 5-year follow-up report. J Contemp Dent Pract. 2020;21(11):1293-7.

126. Ioannidis A, Park JM, Hüsler J, Bomze D, Mühlemann S, Özcan $\mathrm{M}$. An in vitro comparison of the marginal and internal adaptation of ultrathin occlusal veneers made of 3D-printed zirconia, milled zirconia, and heat-pressed lithium disilicate. J Prosthet Dent. 2021;S0022-3913(20):30722-8. https://doi.org/10.1016/j. prosdent.2020.09.053 Epub ahead of print.

127. Alnakib Y, Alsaady A. Influence of ceramic and substrate types on the microleakage of aged porcelain laminate veneers. Clin Cosmet Investig Dent. 2021;13:67-76.

128. McClelland JR. The decalcification of human tooth enamel. Dental Cosmos. 1926;68:127-32.

129. Noyes HJ. Dental caries and the orthodontic patient. JADA. 1936;24:1243.

130. Box HK. The maintenance of enamel integrity during orthodontic treatment. Am J Orthod. 1940;26:1138-45.

131. Gorelick L, Geiger AM, Gwinnett AJ. Incidence of white spot formation after bonding and banding. Am J Orthod. 1982;81(2):93-8.

132. Waugh LM. Orthodontic profiles: John Valentine Mershon. Am J Orthod Dentofac Orthop. 2015;147(5):530-3. 
133. Hsieh TJ, Pinskaya Y, Roberts WE. Assessment of orthodontic treatment outcomes: early treatment versus late treatment. Angle Orthod. 2005;75(2):162-70.

134. Burstone CJ. The precision lingual arch: hinge cap attachment. J Clin Orthod. 1994;28(3):151-8.

135. Tsetsilas M, Konermann AC, Keilig L, Reimann S, Jäger A, Bourauel C. Symmetric and asymmetric expansion of molars using a Burstone-type transpalatal arch. Biomechanical and clinical analysis. J Orofac Orthop. 2015;76(5):377-90.
136. Odom WM. Mixed dentition treatment with cervical traction and lower lingual arch. Angle Orthod. 1983;53(4):329-42.

137. Oh H, Baumrind S, Korn EL, Dugoni S, Boero R, Aubert M, Boyd R. A retrospective study of Class II mixed-dentition treatment. Angle Orthod. 2017;87(1):56-67.

Publisher's Note Springer Nature remains neutral with regard to jurisdictional claims in published maps and institutional affiliations. 